\title{
Employee Satisfaction And Shareholder Returns
}

\author{
Misty Burnett, Webster University \\ Roger J. Best (E-mail: best@cmsu1.cmsu.edu), Central Missouri State University
}

\begin{abstract}
We hypothesize that satisfied employees lead to higher returns for shareholders. In particular, we investigate whether inclusion on Fortune magazine's list of "100 Best Companies to Work For" leads to increases in wealth for shareholders. We find no announcement effect associated with the list release date. Although we do find that a subset of firms named to the list in one year generate higher returns (than a matched sample) the following year, we conclude that, ex ante, investors would be unable to consistently profit from any information provided by inclusion on the list. Tests of returns of companies that are dropped from the Fortune list indicate no abnormal performance.
\end{abstract}

\section{Introduction}

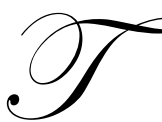

he efficiency wage theory predicts that higher levels of wages lead to higher levels of productivity by employees. Expanding this to an "efficiency compensation theory" as in Meyer et al. (2001) implies that a well-constructed compensation package will enhance productivity through attraction of higher levels of talent, increased effort, and reduced turnover. In general, relative to companies with less-satisfactory compensation packages, employees who are well-satisfied with their compensation package (and work environment) should be expected to generate greater levels of productivity. The result for shareholders, therefore, should be relatively higher levels of return. The purpose of our paper is to determine whether 'satisfied' employees-that is, employees who indicate (collectively) that their company is an excellent one to work for, lead to increased wealth for shareholders.

Employee satisfaction may arise from a number of sources including a high level of wages, excellent company-provided benefits (e.g., educational offerings/reimbursements, health care, on-site childcare, counseling services, etc.), opportunities for within-company mobility, and an innovative or creative work environment. Each of these offerings is costly to the firm, however. Indeed, prior research has indicated that while some policies may enhance shareholder wealth, others, at best, may not benefit shareholders, and, in some instances may reduce shareholder wealth.

For example, Levine (1992) and Wadhwani and Wall (1992) find a positive correlation between wages and productivity, implying greater levels of wages lead to enhanced productivity. Jones and Murrell (2001) find that firms named to Working Mother magazine's list of “America's Most Family-Friendly Companies" for the first time have a positive and significant mean abnormal return during the announcement period. The Working Mother criterion for inclusion are relative wages, advancement opportunities for women, on-site childcare, and other familyfriendly benefits. Thus, market participants infer that these companies' employees are (or will be) more productive than those in other firms. Perry-Smith and Blum (2000) find that companies with greater levels of family-friendly policies exhibit higher levels of product quality, increases in market share, and increases in profits. On the other hand, Meyer, et al. (2001) find that, while policies such as leave of absence to care for family members and adoption benefits increase profitability, more common benefits such as on-site childcare and job sharing negatively affect profits. Also, Filbeck (2001) finds a significantly negative mean abnormal return to the announcement of inclusion on Mother Jones magazine's "20 Better Places to Work." This list includes companies that are environment- 
friendly, provide innovative benefits, and have satisfied employees. Filbeck (2001) also finds that these firms do not perform significantly better than a matched sample of firms in the calender year following the announcement. ${ }^{1}$

To further investigate the relation between employee satisfaction and shareholder wealth, we examine the announcement effect and post-announcement returns of a group of companies named to Fortune magazine's "100 Best Companies to Work For" list for the years 1998-2000. Firms named to the 1998 list are examined by Chan, Gee and Steiner (2000) over the year prior to the list announcement. Using a variety of performance measures, they find that firms on the list have better relative performance prior to the list announcement. ${ }^{2}$ In our study, we find no evidence of abnormal returns surrounding the announcement of inclusion on the list. Overall, during the year following inclusion on the list, firms outperform matched firms on average. Interestingly, however, this result holds only for those firms named to the 1999 list. In fact, further examination shows that only those firms that appear on both the 1998 and the 1999 list exhibit superior stock returns for the eleven months following release of the 1999 list.

\section{Data And Methodology}

We collect our sample from the 1998, 1999 and 2000 Fortune magazine's list of "100 Best Companies to Work For." Fortune selects the final list of 100 companies after receiving survey responses from employees that indicate the company is an exceptional employer. We infer, therefore, that companies rated highly by their employees are companies that have satisfied employees. This allows us to determine whether companies with satisfied employees generate greater returns for their shareholders. The list appears in January in Fortune each year, but is released (through news items) in mid-December of the preceding year.

Inclusion in our sample requires that several criteria be met. First, the company must be publicly traded with historical financial information available from Research Insight (Compustat) and Commodity Systems, Incorporated (through Yahoo! Finance). For the announcement return analysis, companies must have stock return information from 170 days prior to 5 days after the initial announcement of the Fortune list. Second, financial data must be available for the fiscal years prior and subsequent to inclusion on the list. Finally, for the announcement return analysis, no confounding news items must occur during the 20 day window surrounding the list announcement. We search the Lexis-Nexis news wire database to determine whether these contemporaneous announcements exist.

We use a number of tests to determine whether shareholders of the identified companies benefit from having satisfied employees. First, we examine whether there is an announcement effect associated with inclusion on the Fortune list. If inclusion provides new information to market participants, a non-zero return should accompany the Fortune announcement. For example, a positive abnormal return would be consistent with an efficient compensation theory. If markets are informationally efficient, however, we may observe no abnormal return (as employee satisfaction would already have been inferred by market participants). We identify the list release date (as opposed to the official publication date, which follows the release date by a number of weeks) by searching Lexis-Nexis. We then use the event study methodology of Dodd and Warner (1983) to calculate abnormal returns for each company for the two-day window including the day of and day following the release of the list.

Our second test is to determine whether announcement of inclusion on the Fortune list represents a longerterm buying opportunity for market participants. We do this by examining the 11-month holding period return following the list announcement. Similar to Barber and Lyon (1997), we construct a portfolio of matched firms by identifying firms that are within $70 \%$ and $130 \%$ of the market value of the particular sample firm. We measure market value at the end of December in the year prior to the official publication date (e.g., December 1997 for the 1998 list). From this group, we then choose the firm with the book-to-market ratio that is closest to the book-tomarket of the sample firm. We calculate book-to-market at the end of June in the year prior to the list publication date. ${ }^{3}$ A key difference in our procedure is that we match also on the basis of SIC code. We first examine all firms with the same 4-digit SIC as the sample firm. If no firms in this group have a market value within the Barber and Lyon (1997) market value range (+/- 30\% of the sample firm), we check all firms with the same 3-digit SIC code. If there are no appropriate matches at the 3-digit level, we then check all firms with the same 2-digit SIC code. ${ }^{4}$ For each sample firm and control firm, we collect the end of month price (and any dividends) from Research Insight for 
the month of list release (December) through the following November. We use November of the following year (instead of December) to avoid any information effects associated with the release of the next year's list by Fortune. We then calculate the monthly return (for January through November) for each firm and compute the abnormal holding period return (AHPR) for each sample company $i$ as

$$
A H P R_{i}=\prod_{t=1}^{11}\left(1+R_{i t}\right)-\prod_{t=1}^{11}\left(1+R_{c t}\right)
$$

where $R_{i t}$ is the return on sample firm $i$ in month $\mathrm{t}$ and $R_{c t}$ is the return on control firm $c$ in month t. Market efficiency implies that there would be no abnormal returns subsequent to the list release.

Finally, we examine the long-term returns for companies that fail to make the Fortune list in the year following an appearance on the list. It is possible that failure to make the list provides a "leading indicator" of future returns for the company. That is, if a firm fails to make the Fortune list after having done so in the previous year, market participants may infer that employees are less satisfied than before. Less satisfied employees may be less productive, which would lead to a longer-term under performance of the company.

\section{Results}

Table 1 includes a breakdown of the sample of public firms from the Fortune list by year and SIC code. As shown, there are 60 firms with available information from the 1998 list, 58 from the 1999 list, and 54 from the 2000 list. $^{5}$ Thus, our sample involves 172 public (non-unique) companies over the three year period. As some firms appear on the list in more than one year, we have a total of 100 unique firms in our sample. Based on SIC code groupings and a review of the list of firms, there is some evidence of clustering in the sample. Of the 30 firms listed in the 7000-7999 SIC code range, all are computer hardware/software or internet related ("high-tech") firms. An additional 19 firms listed in the 3000-3999 range are also high-tech. Thus, perhaps reflective of the time period in our study, approximately $30 \%$ of our sample would be considered high-tech firms. Additionally, there are 30 financial firms (banks, insurance companies and brokerages) in our full sample. Given the indication of clustering in the hightechnology and financial areas, we modify the Barber and Lyon (1997) methodology to match on the basis of SIC code as described previously.

\section{Table 1: Sample Firms by SIC Code}

The sample consists of firms with available information from Fortune magazine's "100 Best Companies to Work For". SIC Code is collected from Research Insight.

\begin{tabular}{|l|c|c|c|}
\hline \hline SIC Code & $\mathbf{1 9 9 8}$ & $\mathbf{1 9 9 9}$ & $\mathbf{2 0 0 0}$ \\
\hline $1000-1999$ & 0 & 1 & 0 \\
\hline $2000-2999$ & 14 & 8 & 10 \\
\hline $3000-3999$ & 24 & 15 & 12 \\
\hline $4000-4999$ & 2 & 3 & 3 \\
\hline $5000-5999$ & 5 & 9 & 6 \\
\hline $6000-6999$ & 9 & 9 & 12 \\
\hline $7000-7999$ & 6 & 13 & 11 \\
\hline Total & 60 & 58 & 54 \\
\hline \hline
\end{tabular}

In Table 2, we provide the average and median values for market value of equity (measured in December of the year prior to the list publication date) and book-to-market ratio (measured at the end of June prior to the publication date) for the sample firms and for the matched firms (for the long-term return analysis). We are able to match 72 firms (42\%) at the 4-digit SIC level, 33 (19\%) at the 3-digit level, and $67(39 \%)$ at the 2-digit level. The average (median) sample firm is large, with a market value greater than $\$ 32$ billion ( $\$ 7.5$ billion). This likely results from 
Fortune's requirement that a company must have been in operation for 10 years before it could be considered for the list. Because of the difficulty in matching firms simultaneously on SIC code, market value and book-to-market ratio, the average matched firm is significantly smaller than the average sample firm. ${ }^{6}$ The average (median) book-tomarket ratio for the sample is 0.2407 (0.2005). Although not reported in tabular form, the average book-to-market ratio for our sample is (statistically) smaller than for all firms with available data on Research Insight.

Table 2: Market Value and Book-to-Market for Sample and Matched Firms

The sample consists of firms with available information from Fortune magazine's " 100 Best Companies to Work For". Market Value is measured in thousands and is computed at the end of the month in which the list is released. Book-to-market is calculated six months prior to the list publication month.

\begin{tabular}{|l|l|l|l|}
\hline \hline Variable & Sample Firms & Matched Firms & T-test for Difference \\
\hline Market Value & & & \\
\hline $\begin{array}{l}\text { Mean } \\
\text { Median) }\end{array}$ & $32,295,634$ & $17,227,827$ & $2.648 * * *$ \\
$(7,587,239)$ & $(4,411,998)$ & \\
\hline Min & 35,417 & 26,550 & \\
\hline Max & $366,498,310$ & $194,455,910$ & \\
\hline Book-to-Market & & & \\
\hline Mean & 0.2407 & 0.2497 & -0.502 \\
Median) & $(0.2005)$ & $(0.2140)$ & \\
\hline Min & 0.0130 & 0.0230 & \\
\hline Max & 0.8980 & 1.147 & \\
\hline \hline
\end{tabular}

$* * *$ Significant at $1 \%$

In Table 3, we list abnormal returns and their statistical significance from the announcement return analysis. After removing companies with contemporaneous announcements (such as earnings announcements), we have a total of 136 firms. The sample mean abnormal return for all firms is essentially zero, and, in fact, is statistically indistinguishable from zero. We find a similar result for each year in our sample as well. Although not reported in the table, we also segment the sample by whether the sample firm appears on the Fortune list in the previous year. None of these subsample average abnormal returns are statistically different from zero. Thus, unlike Filbeck's (2000) finding of a negative reaction to inclusion on Mother Jones' list and Jones and Murrell's (2001) positive return to inclusion on the Working Mother list, it appears that inclusion on the Fortune list provides no information to shareholders on average.

Table 3: Announcement Returns

The sample includes firms named to Fortune magazine's "100 Best Companies to Work For." Abnormal returns (AR) and test statistics are computed as in Dodd and Warner (1983). The event window is the two day window that includes the list announcement date and the following trading day. The list release date is determine from the Lexis-Nexis news wire service.

\begin{tabular}{|l|c|c|c|}
\hline \hline List Year & Sample Size & $\begin{array}{c}\text { Mean Abnormal } \\
\text { Return }\end{array}$ & Z-score \\
\hline 1998 & 47 & $0.128 \%$ & 0.112 \\
\hline 1999 & 47 & $-0.270 \%$ & 0.448 \\
\hline 2000 & 42 & $0.467 \%$ & 0.810 \\
\hline All & 136 & $0.093 \%$ & 0.779 \\
\hline \hline
\end{tabular}


Lack of significant announcement returns implies that either investors have already impounded the impact of employee satisfaction in stock prices, satisfied employees do not enhance shareholder wealth, or market participants are slow in reacting to news of employee satisfaction. We examine this latter possibility by determining whether investors could earn abnormal long-term returns by creating a portfolio of the firms identified by Fortune. We report these results in Table 4. Using the methodology of Barber and Lyon (1997), we analyze the post-listrelease 11-month abnormal holding period return (AHPR) for the set of 172 (non-unique) firms for which we have data that appear on the Fortune list in 1998, 1999 or 2000. As shown, the mean AHPR for these firms is 11.16\%. With a t-statistic value of 2.463 , the mean is significantly different from zero at the $5 \%$ level.

Table 4: Mean Percentage Abnormal Holding Period Returns

\begin{abstract}
The sample includes firms that appear on the Fortune magazine's "Best Companies to Work for." Matched firms are matched on the basis on SIC code, market value of equity and book-to-market ratio. Abnormal holding period returns (AHPRs) are calculated as compounded monthly holding period returns of the sample firms from the end of December through the end November in the following year minus the compounded monthly return of the matched firms over the same time horizon. T-scores (indicating whether the mean is different than zero) and number of observations are in parentheses. Repeating firms ("First-time" Firms) are those firms that appear (do not appear) on the Fortune list in the previous year (1998 firms are excluded).
\end{abstract}

\begin{tabular}{|l|l|l|l|}
\hline \hline Year & All Firms & Repeating Firms & "First-time" Firms \\
\hline All Years & 11.16 & 13.83 & 15.41 \\
& $\left(2.463^{* *}, 172\right)$ & $(1.633,73)$ & $\left(1.737^{*}, 39\right)$ \\
\hline 1998 & 5.15 & $\mathrm{n} / \mathrm{a}$ & $\mathrm{n} / \mathrm{a}$ \\
& $(0.969,60)$ & & \\
\hline 1999 & 21.55 & 24.38 & 16.58 \\
& $\left(2.195^{* *}, 58\right)$ & $\left(1.808^{*}, 37\right)$ & $(1.275,21)$ \\
\hline 2000 & 6.68 & 2.99 & 14.05 \\
& $(0.870,54)$ & $(0.305,36)$ & $(1.191,18)$ \\
\hline \hline
\end{tabular}

**Significant at 5\%, * Significant at 10\%

In order to determine the robustness of the full sample significance, we segment the sample according to whether a firm appears on the Fortune list in the previous year. If investors naively anticipate that a firm will reappear on future lists, there may be a diminishing marginal effect to being named to the list. 1998 is the first year of publication of the list in Fortune. Thus, we check the firms on the 1999 list to determine whether any of these appear on the 1998 list. We also check the 2000 list to determine if any of these firms appear on the 1999 list. Of the 58 firms we use from the 1999 list, 37 also appear on the 1998 list. Among the 54 firms in our sample from the 2000 list, 36 are also on the 1999 list. Thus, a total of 73 firms are "repeating" from the previous year, while 39 do not appear on the previous year's list ("first-time" firms). The first-time firms exhibit a statistically significant mean AHPR of $15.41 \%$. Repeating firms have an average AHPR of $13.83 \%$ over the year subsequent to inclusion on the Fortune list. With a t-value of 1.633 , however, this mean is statistically insignificant at conventional levels. A t-test for differences (not reported) indicates that these means are not significantly different, however.

To further investigate the AHPR results, we segment the sample by the year in which the list is published. As indicated in Table 4, only those firms that appear on the 1999 list have a subsequent significant mean AHPR. The mean AHPR of $21.55 \%$ for these firms is significantly different from zero at the 5\% level. It appears, however, that this significance is driven primarily by those firms that are repeats from the 1998 list. These 37 repeating firms have a mean AHPR of more than $24 \%$, which is significant at the $10 \%$ level. Thus, only a subset of firms named to the Fortune "100 Best Companies to Work For" appear to generate significantly higher returns than a set of matched firms in the 11 months following the list announcement. Ex ante, there appears to be no discernable characteristic (other than repeating from the 1998 list) which would allow an investor to conclude these firms would exhibit superior returns. Given the lack of superior returns for firms which appear on the 2000 list, it appears that no trading rule could be developed using the Fortune list. $^{7}$ 
As a final test, we examine the mean AHPR for firms that are dropped from the Fortune list after one (or more) appearances on the list. Using the 1998 list as the base, we check the 1999 list and identify those firms from the 1998 list which fail to appear on the 1999 list. We also compare the 2000 list to the 1999 list to identify firms that are dropped after the 1999 list. We refer to these firms as "dropped" firms. A total of 49 companies with available data fall into this category. Table 5 includes the mean raw return and AHPR for these firms and for the 73 firms identified previously as repeating firms. ${ }^{8}$ The dropped firms have a mean (raw) return of $9.7 \%$ in the year after failing to make the Fortune list. Although this is less than the mean return of $14.9 \%$ earned by repeating firms, a t-test reveals that the mean returns are indistinguishable. Similar results hold for the AHPRs. Although the sample mean AHPR for the repeating firms is much larger than the sample mean AHPR for the dropped firms (13.8\% versus $-1.1 \%$ ), the t-statistic of -1.17 is not significant at conventional levels. Based on these results, firms that are dropped from the Fortune list perform no worse than firms that repeat or a matched sample in the year after failing to make the list.

Table 5: Average Returns for Firms Dropped from the Fortune List

\begin{abstract}
Firms that fail to appear on the Fortune list in the subsequent year are referred to as "Drops." Firms repeating from the previous year are referred to as "Repeaters." Returns are calculated as compounded monthly holding period returns from the end of December through the end November in the following year. These returns are measured over the 11 months subsequent to the "Drops" not appearing on the Fortune list. Abnormal holding period return (AHPR) is calculated as the return of the sample firm minus the return of a matched firm over the same time horizon. Firms are matched on the basis of SIC code, market value of equity and book-to-market ratio.
\end{abstract}

\begin{tabular}{|l|l|l|l|}
\hline \hline & Raw Return & AHPR & AHPR t-test \\
\hline Dropped & 9.70 & -1.14 & -0.127 \\
\hline Repeaters & 14.89 & 13.83 & 1.633 \\
\hline $\begin{array}{l}\text { t-test for difference } \\
\text { (Drops - Repeaters) }\end{array}$ & -0.548 & -1.170 & \\
\hline \hline
\end{tabular}

\title{
4. Summary Of Findings And Conclusion
}

We find that, on average, there is no announcement return associated with inclusion on Fortune magazine's list of "100 Best Companies to Work For" for the years 1998-2000. This result is contrary to previous studies which find significant market reactions to inclusions on similar lists. We further examine whether firms which appear on Fortune magazine's list earn abnormal holding period returns during the 11 months after the list is released. Although the full sample of firms appears to statistically outperform a control sample, our investigation indicates that only a subset of firms drive the full sample results. Ex ante, there appears to be no logical manner in which to choose those firms which generate superior performance. As a final test, we examine the performance of firms that are named to the Fortune list in a given year and then fail to make the list in the following year. For the 11 months following the period in which they fail to make the list, the dropped firms have similar stock returns to both a matched sample and to firms that repeat on the Fortune list.

Although previous studies find significant stock price reactions for firms named to similar lists, we conclude that inclusion on the Fortune magazine list of "100 Best Companies to Work For" provides no information to investors regarding short-term or long-term stock returns. We cannot conclude that our results are contrary to the efficient "compensation" theory, however, as information concerning employee satisfaction may already be reflected in the stock price prior to announcements of the Fortune lists. 


\section{References}

1. Barber, B. M. and J. D. Lyon, 1997, "Detecting long-run abnormal stock returns: The empirical power and specification of test statistics", Journal of Financial Economics, 43, 341-372.

2. Chan, K. C., M. V. Gee, and T. L. Steiner, 2000, "Employee happiness and corporate financial performance", Financial Practice and Education, 10, 47-52.

3. Dodd, P. and J. B. Warner, 1983, "On corporate governance: A study of proxy contests". Journal of Financial Economics, 11, 401-438.

4. Filbeck, G., 2001, "Mother Jones: Do better places to work imply better places to invest?", Review of Financial Economics, 10, 57-70.

5. Jones, R. and A. J. Murrell, 2001, "Signaling positive social corporate performance: An event study of family-friendly firms", Business and Society, 40, 59-78.

6. Levine, D., 1992, "Can wage increases pay for themselves? Tests with a production function", Economic Journal, 1102-1115.

7. Lie, E., 2001, "Detecting abnormal operating performance: Revisited", Financial Management, 30, 77-92.

8. Meyer, C. S., S. Mukerjee and A. Sestero, 2001, "Work-family benefits: Which ones maximize profits?", Journal of Managerial Issues, 13, 28-44.

9. Perry-Smith, J. E. and T. C. Blum, 2000, "Work-family human resource bundles and perceived organizational performance", Academy of Management Journal, 43, 1107-1117.

10. Wadhwani, S. B. and M. Wall, 1991, "A direct test of the efficiency wage model using U. K. micro-data", Oxford Economic Papers, 43, 529-548.

\section{Endnotes}

1. Caution must be used when generalizing these results, however, as Filbeck (2001) has only 12 sample firms in his study.

2. Additionally, Fortune indicates that the publicly traded firms on its list have higher returns than the Standard and Poor's 500 index in the year prior to inclusion on the list.

3. For example, for the 1999 list (which is actually published in December 1998), we use the June 1998 bookto-market ratio.

4. The SIC restriction limits the available matches. To prevent selecting matches with similar market values (and SIC codes) but greatly dissimilar book-to-market ratios, we restrict the book-to-market ratio of the match to be within $25 \%$ of the value of the sample firm's book-to-market ratio. This presents a problem because some of our sample firms are large, and no appropriate matches for both size and book-to-market are available. Thus, there are some observations in which the SIC code and book-to-market criteria are satisfied, but the size restriction is not.

5. Microsoft appears in all three years, but we exclude it because of on-going litigation with the federal government.

6. We address this problem by removing sample firms that have the greatest positive size differences (relative to the matched firms) until the average size difference is statistically indistinguishable from zero. The test results from this reduced sample are almost identical numerically to the results from the full sample. Thus, we report only the full sample results.

7. We also construct a pooled regression analysis with AHPR as the dependent variable and MVE, book-tomarket ratio, dummy variables indicating repeating firms and list year, and the Fortune rank (i.e., a number 1-100 where 1 is the firm identified by Fortune as being the best company to work for). None of the coefficients are statistically significant.

8. We construct a matched set of firms for the dropped firms using the variation of the Barber and Lyon (1997) methodology described previously. 
Notes 


\section{Do Not Print This Page}

1. Caution must be used when generalizing these results, however, as Filbeck (2001) has only 12 sample firms in his study.

2. Additionally, Fortune indicates that the publicly traded firms on its list have higher returns than the Standard and Poor's 500 index in the year prior to inclusion on the list.

3. For example, for the 1999 list (which is actually published in December 1998), we use the June 1998 book-tomarket ratio.

4. The SIC restriction limits the available matches. To prevent selecting matches with similar market values (and SIC codes) but greatly dissimilar book-to-market ratios, we restrict the book-to-market ratio of the match to be within $25 \%$ of the value of the sample firm's book-to-market ratio. This presents a problem because some of our sample firms are large, and no appropriate matches for both size and book-to-market are available. Thus, there are some observations in which the SIC code and book-to-market criteria are satisfied, but the size restriction is not.

5. Microsoft appears in all three years, but we exclude it because of on-going litigation with the federal government.

6. We address this problem by removing sample firms that have the greatest positive size differences (relative to the matched firms) until the average size difference is statistically indistinguishable from zero. The test results from this reduced sample are almost identical numerically to the results from the full sample. Thus, we report only the full sample results.

7. We also construct a pooled regression analysis with AHPR as the dependent variable and MVE, book-to-market ratio, dummy variables indicating repeating firms and list year, and the Fortune rank (i.e., a number 1-100 where 1 is the firm identified by Fortune as being the best company to work for). None of the coefficients are statistically significant.

8. We construct a matched set of firms for the dropped firms using the variation of the Barber and Lyon (1997) methodology described previously. 